\title{
Large Vertex Epidural Hematoma: Case Report and Review of Surgical Approaches
}

\section{Volumoso hematoma epidural do vértex: relato de caso e revisão de estratégias cirúrgicas}

\author{
Angelo R. Silva Neto ${ }^{1}$ Luana Medeiros ${ }^{1}$ Fábio B. Silva ${ }^{1}$ Renata N. Velloso ${ }^{1}$ \\ ${ }^{1}$ Departament of Integrative Medicine, Hospital Universitário Onofre \\ Lopes, Universidade Federal do Rio Grande do Norte, Natal, RN, Brazil \\ Arq Bras Neurocir 2019;38:324-327. \\ Address for correspondence Angelo R. Silva Neto, MD, PhD, \\ Departamento de Medicina Integrada, Hospital Universitário Onofre \\ Lopes, Universidade Federal do Rio Grande do Norte, Avenida Nilo \\ Peçanha 620, Petrópolis, 59012-300, Natal, RN, Brazil \\ (e-mail: angelorsn@gmail.com).
}

\begin{abstract}
Keywords

- vertex epidural hematoma

- traumatic brain injury

- craniotomy
\end{abstract}

Resumo
Vertex epidural hematomas (VEHs) are a special clinical entity due to their clinical presentation, vascular etiology and options of surgical approach. The clinical suspicion involves recognizing the mechanism of the injury and the correct visualization of the hematoma in computed tomography (CT) coronal sequences. In the present article, we describe a case of a very large $(146 \mathrm{~mL}) \mathrm{VEH}$ with central brain herniation, and provide a technical note on the surgical planning and treatment. A 34-year-old male patient was admitted to the hospital after an injury on the left superior parietal region. The Glasgow coma scale score was 6 , and the left pupil of the patient was dilated. The CT scan showed a large epidural hematoma on the vertex between the coronal e lambdoid sutures, and a fracture over the sagittal suture. During the surgery, multiple burr holes were made laterally to the sagittal suture, and after inspection and no visualization of bleeding in the superior sagittal sinus (SSS), we performed a standard biparietal craniotomy. The patient was discharged three days after the surgery without any deficits. Currently, with the improvement in imaging modalities, more cases of VEH are being identified. Identifying the etiology prior to the craniotomy is challenging in severe cases. Tears in the SSS can bleed profusely, and they demand strategies during the craniotomy. With multiple burr holes parallel to the sagittal suture, we can visualize whether there is bleeding in the SSS and design a craniotomy with or without a central osseous bridge to anchor the dura. Neurosurgeons must be prepared to plan a surgical strategy in cases of large VEHs. Due to its rare frequency and bleeding risks, VEHs are considered challenging.

O hematoma epidural do vértex (HEV) é uma entidade clínica especial particularmente por sua sintomatologia, etiologia vascular e tratamento. A suspeita clínica envolve o reconhecimento do mecanismo do trauma e a correta visualização de sequências received

December 13, 2018

accepted

July 1,2019
DOI https://doi.org/

10.1055/s-0039-1695760. ISSN 0103-5355.
Copyright @ 2019 by Thieme Revinter

Publicações Ltda, Rio de Janeiro, Brazil
License terms

(c) $(1) \$$ 


\section{Palavras-chave}

- hematoma epidural do vértex

- traumatismos craniocerebrais

- craniotomia coronais na tomografia. Descrevemos no presente artigo um paciente com volumoso HEV (146 mL) com herniação central e detalhes do planejamento cirúrgico. Paciente de 34 anos, do sexo masculino, deu entrada no hospital após agressão na região parietal esquerda superior. A escala de coma de Glasgow foi de 6 pontos, com dilatação pupilar esquerda. A tomografia demonstrou grande HEV entre as suturas coronal e sagital associado a fratura. Na cirurgia, realizamos múltiplas trepanações lateralmente à sutura sagital e, após inspeção do seio sagital superior (SSS), fizemos uma ampla craniotomia biparietal. Após 3 dias, o paciente recebeu alta sem déficits. Atualmente, mais casos de HEV são identificados radiologicamente por conta de melhoras nas modalidades de exames radiológicos. Identificar a etiologia antes de realizar a craniotomia é desafiador em casos graves. Lesões no SSS podem apresentar sangramento volumoso, o que exige o uso de estratégias durante a craniotomia. Com múltiplas trepanações paralelas à sutura sagital, podemos antecipar se há ou não sangramento ativo do SSS e desenhar uma craniotomia com ou sem ponte óssea central de ancoramento dural. Neurocirurgiões devem estar preparados para planejar uma estratégia cirúrgica em casos de HEV. Por sua raridade e potencial de sangramento, os HEVs são considerados desafiadores.

\section{Introduction}

Vertex epidural hematomas (VEHs) are extremely rare. They comprise $\sim 1$ to $8 \%$ of all traumatic epidural hematomas. ${ }^{1}$ The diagnosis is difficult, and it is based on cases of inadequacy of orientation in axial head CT scans; therefore, the identification of this type of hematoma is challenging. ${ }^{2,3}$ In many cases, the superior sagittal sinus (SSS) is the main structure involved in the origin of the bleeding. ${ }^{4}$

There are a lot of reported cases of VEH. ${ }^{1,5-7}$ We describe in the present article a rare and extremely large VEH with central brain herniation, and provide a technical note on the surgical planning and treatment.

\section{Case Report}

A 34-year-old male patient was admitted to our hospital after a traumatic aggression on the left superior parietal region by a Wood stick during a discussion. He immediately lost his consciousness, and was intubated and transferred by helicopter to our facility. After 80 minutes, upon admission at the emergency room, a physical examination revealed a dilated left pupil with no reaction to light. He had a Glasgow coma scale (GCS) score of 6 and a subcutaneous hematoma on the vertex scalp. The best motor response was obtained in the arms, which made us investigate traumatic spinal cord injury. Clinically, he presented arterial pressure of $140 / 95 \mathrm{mmHg}$, heart rate of 88 beats/minute, and blood oxygen level $\left(\mathrm{SpO}_{2}\right)$ of $98 \%$, and received $2,000 \mathrm{~mL}$ of crystalloid fluid. A noncontrast brain computed tomography (CT) scan showed a large epidural hematoma on the vertex between the coronal e lambdoid sutures, bilaterally ( - Fig. 1). The volume of the hematoma was of approximately $146 \mathrm{~mL}$. A three-dimensional (3D) CT reconstruction revealed a straight fracture over the sagittal suture extending to the frontal bone (-Fig. 2). No spinal fracture or dislocation was found on the routine CT of the spine. Due to the evident brain herniation in progress and intracranial hypertension, the patient was transferred immediately to the operating room without being submitted to a more accurate study of the vascular damage in the SSS

Surgical procedure: The patient was placed in supine position with a slight flexion of the head. An incision was planned bilaterally at a point between the coronal and lambdoid sutures. After a subperiosteal plane dissection, the parietal bone was exposed, showing a diastatic fracture aligned with the sagittal suture (-Fig. 2). A large bilateral parietal bone flap was made by two anterior burr holes, close to the coronal suture, and close to the midline. The flap was taken out, and the clot was identified and evacuated carefully from the lateral to the medial parts to prevent bleeding from the SSS. There was no injury in the outer surface of the SSS. Dural anchoring sutures were applied around the lateral edges of the craniotomy. The subdural space was inspected to exclude the presence of subdural hematoma, and, at the same time, we inserted saline solution to facilitate dural adhesion to the bone. The flap was secured with sutures, and subgaleal drains were placed.

\section{Postoperative Course}

Recovery was good, with a GCS score of 15 after $24 \mathrm{~h}$. A CT scan of the head after surgery showed a good result and no evidence of mass effect, with minimal residual hematoma (-Fig. 2). By day 5, the patient was discharged successfully, with no additional deficits.

\section{Discussion}

Vertex epidural hematomas are rare and frequently associated to bleeding from the venous sinus, bone fracture or dural diffuse bleeding (arterioles). ${ }^{7}$ They must be considered a special clinical entity because of their presentation and vascular etiology. ${ }^{1}$ Clinical suspicion relies on the symptoms of the 


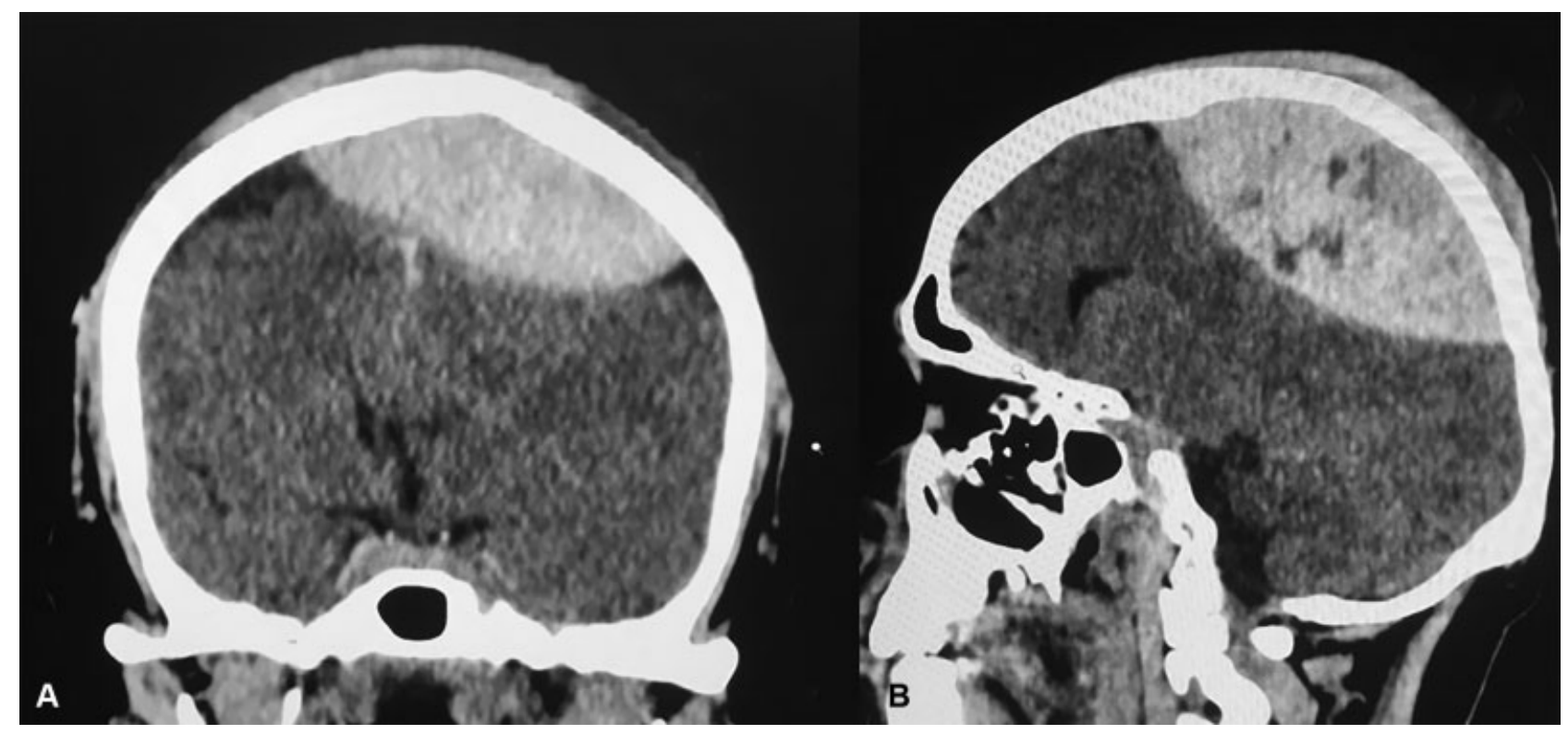

Fig. 1 Large vertex epidural hematoma with central brain herniation and compression of the diencephalic structures. (A) Coronal and (B) sagittal computed tomography (CT) scan sequences.

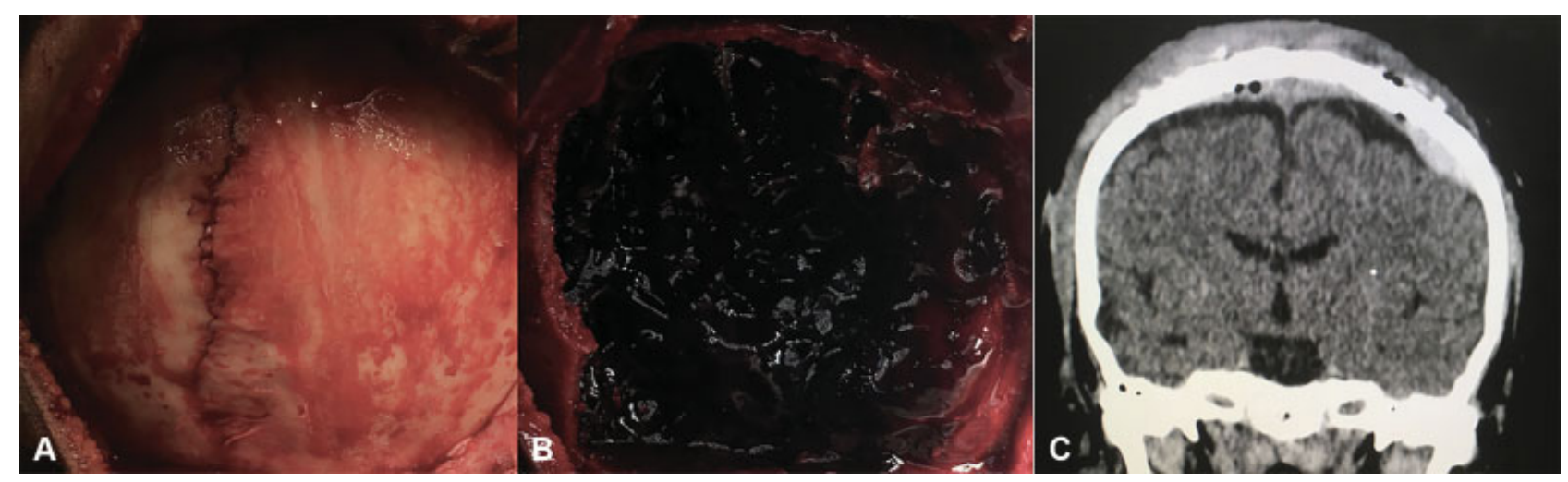

Fig. 2 (A) Intraoperative view of a diastatic fracture of the sagittal suture. (B) After the biparietal craniotomy with visualization of a large epidural hematoma; (C) Coronal CT scan one day after surgery.

patient and on the mechanism of the injury. In cases in which the SSS is damaged, the clinical course is more acute, with elevation of intracranial pressure (ICP) and brain herniation. ${ }^{7,8}$ When the bleeding comes from other sources, the clinical symptoms and the evolution are more indolent.

A wide variety of symptoms can occur in cases of VEH. In the emergency room, weakness in the lower extremities can lead the physicians to mistake the clinical picture for spinal cord injury. In cases of paraplegia after a traumatic brain injury, the possibility of occurrence of VEHs must be considered. If the patient is conscious, awake, a critical volume of 40 to $50 \mathrm{~mL}$ can be treated conservatively. ${ }^{9}$ About $30 \%$ of VEHs reported have a chronic course of symptoms. The block of the cerebrospinal fluid and disruption of the venous drainage can explain the chronic presentation, even with VEHs with small volumes. ${ }^{10}$

Due to its location, VEH can cause compression of the rolandic cortex, with special involvement of the motor control of the lower limbs. ${ }^{5}$ This presentation is usually noted when the course of the hematoma expansion is more subtle and slow. Even if it is secondary to venous structures, VEH can present a large and quick expansion and be restrained by the coronal and lambdoid sutures. In this situation, a pressure vector toward the diencephalon contributes to the depression of the consciousness level.

Coronal CT scan sequences are the ideal method to investigate VEHs. Depending on the orientation of the axis in axial CT scans of the brain, a large VEH may not be visualized, and be masked by surround bone. ${ }^{3}$ This is a particular problem when the patient is studied in sequential (horizontal) scans instead of spiral (helical) scans, and the more cephalic scan planned be out of VEH. ${ }^{2}$ This interface between these two structures with grossly differing density is known to be problematic. When the trauma is on the skull vertex and reveals strong forces, repeating a normal CT scan and finding no evidence of hematoma is a secure option to identify or rule out VEH.

Some authors recommend the use of CT venous angiography before craniotomy to prevent a large bleeding from the SSS 
and thus program a surgical strategy. Cerebral arteriography has been mentioned as an option in cases of chronic evolution due to the rare possibility of occurrence of an arteriovenous fistula. ${ }^{10}$ Before the existence of the $\mathrm{CT}$, finding a dislocation of the SSS from the inner skull table was an evidence of VEH. ${ }^{2}$ Slow blood flow on the SSS is another evidence. In pediatric patients with open fontanels, treatment with aspiration by direct puncture is an alternative approach. ${ }^{2}$

Many authors have described surgical techniques in which a bone bridge is left over the SSS to avoid potential bleeding. ${ }^{1,4}$ That is a consideration if we realize the risks of dealing with the second third of the SSS. Tears over the SSS may complicate the surgery and result in higher morbidity and mortality. ${ }^{1,8}$ Another option that has been mentioned is the interposition of sutures using Teflon pledgets to control profuse SSS bleeding. ${ }^{5}$ In our case, we planned a straight incision over a line between the coronal and lambdoid sutures. A biparietal craniotomy was performed with multiples burr holes beside the sagittal suture. At this point, we didn't see active bleeding coming from the sinus, and we ended up performing a craniotomy without a bridge bar. In our opinion, this strategy can be followed carefully before planning the craniotomy, leaving only a strip of bone over the SSS if active bleeding is visualized under the fractured bone.

We emphasize in the present article that the use of saline infusion for the expansion and elevation of dural gaps has some risks that include infections and the creation of hypertensive subdural collections. Central and peripheral anchoring are still the main options to prevent the accumulation of a new hematoma. When no anchoring point is possible to obtain, the direct repair of the SSS bleeding can be performed by direct pressure with cottonoids, muscle and Gelfoam (Pfizer, New York, NY, US). Even digital pressure is a temporary option. Putting the head in the reverse Trendelenburg position helps prevent air embolism. In rare cases with large sinus lacerations, the use of a Fogarty catheter, sinoraphy with continuous suture, or even grafts can control this problem.

\section{Conclusion}

Neurosurgeons must be prepared to plan a surgical strategy in cases of large VEHs. Due to their rare frequency and bleeding risks, they represent a challenge in cases of emergency surgery.

\section{Conflicts of Interest}

The authors have none to declare.

\section{References}

1 Jones TL, Crocker M, Martin AJ. A surgical strategy for vertex epidural haematoma. Acta Neurochir (Wien) 2011;153(09): 1819-1820

2 Strowitzki M, Eymann R, Schleifer J, Steudel WI. Vertex epidural hematoma with communicating bifrontal subgaleal hematomas treated by percutaneous needle aspiration. Pediatr Neurosurg 2001;35(01):1-4

3 Pomeranz S, Wald U, Zagzag D, Gomori M, Shalit M. Chronic epidural hematoma of the vertex: problems in detection with computed tomography. Surg Neurol 1984;22(04):409-411

4 Fernandes-Cabral DT, Kooshkabadi A, Panesar SS, et al. Surgical Management of Vertex Epidural Hematoma: Technical Case Report and Literature Review. World Neurosurg 2017;103:475-483

5 Liliang PC, Liang CL, Chen HJ, Cheng CH. Vertex epidural haematoma presented with paraplegia. Injury 2001;32(03):252-253

6 Plotkin FR, Burke TF. Vertex epidural hematoma: a diagnostic challenge. Ann Emerg Med 1994;24(02):312-315

7 Haikel LF, Listik S, Rodrigues JC, Viterbo MB, Pereira CA. [Epidural hematoma at the vertex: case report]. Arq Neuropsiquiatr 2005; 63(2A):357-359

8 Nayil K, Laharwal M, Dhar A, Wani A, Ramzan A, Arif S. Vertex epidural hematoma with bilateral abducent nerve palsy: case report and literature review. Turk Neurosurg 2012;22(02):257-260

9 Pang D, Horton JA, Herron JM, Wilberger JE Jr, Vries JK. Nonsurgical management of extradural hematomas in children. J Neurosurg 1983;59(06):958-971

10 Matsumoto K, Akagi K, Abekura M, Tasaki O. Vertex epidural hematoma associated with traumatic arteriovenous fistula of the middle meningeal artery: a case report. Surg Neurol 2001;55(05): 302-304 